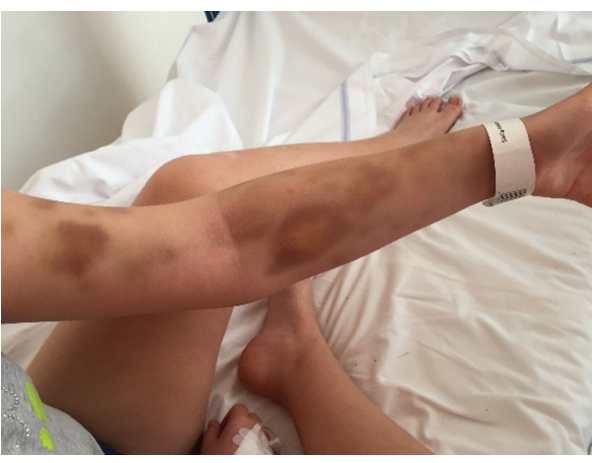

Abstract AB0972 Figure 2

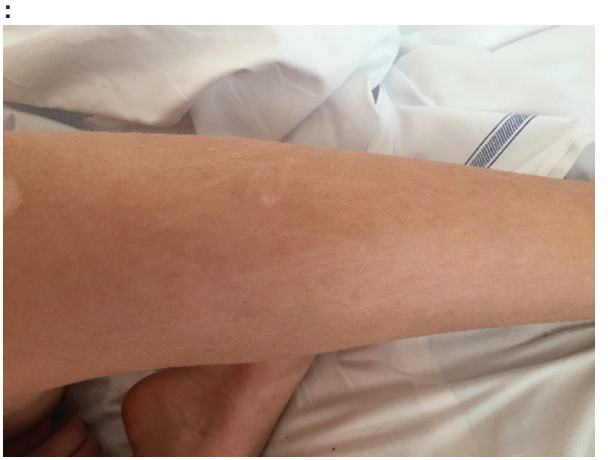

Abstract AB0972 Figure 3

Disclosure of Interests: Lisa Gamalero: None declared, Ilaria Pagnini: None declared, Gabriele Simonini Grant/research support from: Abbvie, Speakers bureau: Abbvie, Rolando Cimaz: None declared, Teresa Giani: None declared

DOI: 10.1136/annrheumdis-2019-eular.4312

\section{AB0973 ATYPICAL KAWASAKI DISEASE SHOCK SYNDROME CASE REPORT: NOT ALL SHOCKS ARE SEPTIC OR TOXIC}

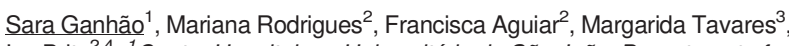
Iva Brito ${ }^{2,4} .{ }^{1}$ Centro Hospitalar e Universitário de São João, Department of Rheumatology, Oporto, Portugal; ${ }^{2}$ Centro Hospitalar e Universitário de São João, Pediatric Rheumatology Unit, Oporto, Portugal; ${ }^{3}$ Centro Hospitalar e Universitário de São João, Pediatric Infectious Diseases Unit, Oporto, Portugal; ${ }^{4}$ Faculty of Medicine of Oporto University, Oporto, Portugal

Background: Kawasaki disease (KD) is an acute, self-limited vasculitis of unknown etiology with peak incidence at 9-12 months of age. The term Kawasaki Disease Shock Syndrome (KDSS) was introduced in 2009 after reports of hemodynamic instability during the acute phase of the illness. Objectives: Present and discuss a rare case of KDSS in an adolescent patient.

Methods: Review of patient's clinical records and scientific literature.

Results: A 12 year-old boy was admitted in the pediatric intensive care unit (ICU) with a 5-day history of high persistent fever, abdominal pain, vomiting and headaches. On examination, he looked ill, was tachycardic and hypotensive with delayed capillary refill, had non-exsudative oropharyngeal erythema, cracked lips, terminal nuchal rigidity, jaundice and small palpable supraclavicular lymph nodes. On day 3 a generalized morbiliform rash and diffuse swelling of the hands became apparent. Blood gas showed metabolic acidosis. He had decreased platelet count of 72,000/ mm3, AST $122 \mathrm{U} / \mathrm{l}$, ALT $192 \mathrm{U} / \mathrm{l}, \mathrm{LDH} 366 \mathrm{U} / \mathrm{L}$, triglycerides $207 \mathrm{mg} / \mathrm{dl}$, total bilirubin $85,5 \mu \mathrm{mol} / \mathrm{l}$ (direct 68,4 ). Renal function, urinalysis and fibrinogen were normal. ESR was $42 \mathrm{~mm} / \mathrm{h}$, CRP was markedly high (268 $\mathrm{mg} / \mathrm{ll}$ ) and ferritin $544 \mathrm{ng} / \mathrm{ml}$. Lumbar puncture revealed mild sterile pleocytosis. Due to progressive hemodynamic instability he required fluid resuscitation, inotropic drugs and mechanical ventilation. Broad-spectrum antibiotherapy was started due to suspected septic shock/streptococcal toxic shock syndrome. IVIG was empirically started $24 \mathrm{~h}$ later due to non- response. Viral screening, all blood and urine cultures and ASO titers were negative. Myelogram revealed no signs of hemophagocytosis, neoplastic changes or growth of microorganisms in culture. Fine needle biopsy of a supraclavicular lymph node showed nonspecific inflammatory changes. Thoracoabdominal scan revealed moderate bilateral pleural effusion, mild hepatoesplenomegaly, retroperitoneal/mesenteric lymphadenopathy. Brain MRI and echocardiogram were normal as well as ophtalmologic evaluation. In the presence of prolonged fevers, mucosal changes, extremity edema and non-specific rash in a severely-ill adolescent with no response to broad spectrum antibiotics and negative cultures, the possibility of KD was raised.

Due to ongoing fevers and inflammation after $36 \mathrm{~h}$ of first IVIG, he received a second IVIG dose $2 \mathrm{~g} / \mathrm{Kg}$, methylprednisolone IV pulses for 3 days and aspirin, with rapid clinical and laboratorial improvement. Within $24 \mathrm{~h}$ the patient was off inoptropic support, $48 \mathrm{~h}$ off mechanical ventilation and 3 days later he was discharged from the ICU. His general condition continued to improve gradually, with increased platelet counts, normalization of liver function and CRP. In this phase, skin desquamation (buttocks/perineal region) was noted. At follow-up, thoracoabdominal angioMRI and serial ecocardiograms were normal. He was weaned off corticosteroids and aspirin without recurrence of symptoms.

Conclusion: In this case, despite the atypical age and lack of some classical signs/symptoms, broad-spectrum antibiotic refractoriness and the described clinical presentation raised the hypothesis of KSSD. Diagnosis can be difficult, especially if shock occurs in incomplete forms of KD, but must be suspected early and treatment promptly started in order to ensure a good prognosis. Clinicians should be aware that thrombocytopenia and hepatitis are risk factors for refractory severe KD. MAS must always be excluded in cases of hemodinamic instability.

\section{REFERENCES}

[1] Kanegaye, et al.

[2] Recognition of a Kawasaki disease shock syndrome. Pediatrics 123:e783e789.

Disclosure of Interests: None declared

DOI: 10.1136/annrheumdis-2019-eular.7039

\section{AB0974 A CASE OF ADENOSINE DEAMINASE 2 DEFICIENCY (DADA2) WITH AN UNCOMMON CLINICAL PRESENTATION AND RESPONSE TO IV IG}

Francesca Garbarino ${ }^{1}$, Roberta Caorsi ${ }^{2}$, Stefano Volpi ${ }^{2}$, Alice Grossi ${ }^{3}$, Isabella Ceccherini ${ }^{3}$, Marco Gattorno'. ${ }^{1}$ Universitå degli studi di Genova, Genova, Italy; ${ }^{2}$ IRCCS Istituto Giannina Gaslini, Clinica Pediatrica e Reumatologia, UOSD Malattie Autoinfiammatorie-Immunodeficienze, Genova, Italy; ${ }^{3}$ RCCS Istituto Giannina Gaslini, UOC Genetica Medica e UOSD Genetica e Genomica delle Malattie Rare, Genova, Italy

Background: DADA2 is an autoinflammatory disease with autosomal recessive inheritance characterized by a heterogeneous clinical phenotype ranging from multisystemic inflammation (fever, polyarteritis nodosa, cerebral stroke, livedo reticularis etc.) to immune-dysregulation and immunodeficiency.

Objectives: To extend the clinical spectrum of DADA2 reporting a case of isolated nonspecific systemic inflammatory syndrome associated with signs of immune-dysregulation in a patient with a novel ADA2 mutation.

Methods: In a patient with nonspecific inflammatory phenotype associated to susceptibility to viral infections, Next Generation Sequencing (NGS) panel was performed; mutations detected were confirmed by Sanger analysis. ADA2 enzymatic activity was analyzed in monocyte isolated from the patient and incubated with adenosine and an ADA1 inhibitor.

Results: The girl, adopted and of Asian origin, began to suffer from nonspecific systemic inflammatory symptoms (persistent fever and arthralgias) at the age of 6 . In past history recurrent respiratory infections and impaired immunological response to viruses (CMV related hepatitis, measles after vaccination) were reported. After few months the patient developed clinical and laboratory findings of $\mathrm{HLH}$ (Hemophagocytic LymphoHistocytosis), confirmed on bone marrow samples; treatment with intravenous (IV) high dose (HD) steroids was started, with prompt response. During steroids tapering fever and systemic inflammation reappeared; antiIL1 treatment (anakinra) was not effective. Immunologic assessment demonstrated mild hypogammaglobulinemia and moderate NK deficiency on lymphocyte subsets. HD IV Immunoglobulins (IG) (2 g/kg every month) allowed to achieve a complete control of the clinical picture; the frequency of administration was progressively reduced to every 4 months due to persistent wellbeing. At the age of 9 , after switching IG to the 
substitutive dosage, the patient experienced Herpes Zoster virus reactivation (requiring prolonged antiviral treatment), followed by the reappearance of the inflammatory phenotype complicated by HLH with neurological involvement (irritability and lethargy), responsive to HD steroids and IG. A later cerebral MRI evidenced a small gliotic area in left Centrum Ovale. After steroids suspension, monthly HD IV IG administrations maintained clinical remission. Further immunological studies confirmed a reduction of NK cells with normal function. Hereditary HLH, Autoimmune Lympho-Proliferative Syndrome (ALPS) and main primary immunodeficiencies were ruled out. Given the clinical picture, a large NGS diagnostic panel (courtesy by K. Botzug, Vienna) for autoinflammatory diseases and immunodeficiencies was performed revealing the homozygous LEU141PRO ADA2 mutation, confirmed by Sanger analysis. Being this mutation novel, an ADA2 enzymatic activity test was performed revealing a complete loss of ADA2 activity. The parents refused anti-TNF treatment and the patient is still on monthly HD IG with a complete wellbeing after 3 years of follow-up.

Conclusion: The current report enlarges the clinical spectrum associated with DADA2 to a persistent unspecific inflammatory syndrome, complicated by $\mathrm{HLH}$. This case further emphasizes the possibility that NGS could unravel unusual phenotypes of already known inflammatory syndromes. Even if further reports are required, the response to $\mathrm{HD}$ IG observed in the present case it is of interest. Even if anti-TNF is the treatment of choice HD IG could be a possible treatment in DADA2, especially during the acute phase.

\section{REFERENCES}

[1] Caorsi R, et al. Ann Rheum Dis. 2017 76(10):1648-1656

Disclosure of Interests: Francesca Garbarino: None declared, Roberta Caorsi: None declared, Stefano Volpi: None declared, Alice Grossi: None declared, Isabella Ceccherini: None declared, Marco Gattorno Grant/ research support from: MG has received unrestricted grants from Sobi and Novartis

DOI: 10.1136/annrheumdis-2019-eular.5187

\section{AB0975 \\ INITIAL BIOLOGICAL THERAPY RESPONSE IN PATIENTS WITH SUSPECTED AUTOINFLAMAMTORY DISEASE}

Laura Fernández Silveira ${ }^{1}$, Maria Isabel García Ruiz-Santa Quiteria ${ }^{1}$, Marisol Camacho Lovillo ${ }^{1}$, Paula Sánchez Moreno ${ }^{1}$, Marco Antonio Montes Cano ${ }^{2}$, Jose Manuel Lucena Soto ${ }^{2}$, Jose Bernabeu Wittel ${ }^{3}$, Beatriz Muñoz Cabello ${ }^{1}$, Julia Fijo López-Viota ${ }^{1}$, Olaf Neth ${ }^{1}$. ${ }^{1}$ Hospital Universitario Virgen del Rocío, Pediatrician, Sevilla, Spain; ${ }^{2}$ Hospital Universitario Virgen del Rocío, Inmunologist, Sevilla, Spain; ${ }^{3}$ Hospital Universitario Virgen del Rocío, Dermatology, Sevilla, Spain

Background: The choice of the initial biological therapy for patients with suspected autoinflammatory diseases and not conclusive genetic test remains challenging.

Objectives: To assess the clinical response to the initial biological therapy in pediatric patients with suspected autoinflammatory disease with no genetic diagnosis.

Methods: We retrospectively reviewed the clinical charts of patients followed in our clinic who started empirical biological therapy after being diagnosed with suspected autoinflammatory disease(SAID) due to the intensity of their symptoms and no response to colchicin or FAMEs. Next generation sequencing using an immune deficiency/dysregulation(115 genes) and autoinflammatory panel(12 genes) was negative/inconclusive in all patients.

\begin{tabular}{|c|c|c|c|c|c|c|}
\hline & Mean & SD & Median & IQR & Min & Max \\
\hline PCR max mg/L & 199.4 & 134 & 181 & 190 & 39 & 440 \\
\hline VSG $1 \mathrm{~h} \max$ & 89.7 & 29.6 & 86 & 32 & 44 & 140 \\
\hline Leukocytes/ul & 25942 & 9950 & 25105 & 9450 & 11670 & 45200 \\
\hline Neuthrophils/ul & 16132 & 6692 & 16250 & 9450 & 6500 & 25300 \\
\hline Lymphocytes/ul & 1518 & 1050 & 1275 & 1350 & 200 & 3300 \\
\hline $\begin{array}{l}\text { Haemoglobin } \\
\text { (g/dl) }\end{array}$ & 9.6 & 2.1 & 10 & 2.75 & 6.2 & 12.8 \\
\hline $\begin{array}{l}\text { Platelets/ul } \\
\text { (max) }\end{array}$ & 603375 & 225317 & 560000 & 198000 & 25000 & 100300 \\
\hline $\begin{array}{l}\text { Platelets/ul } \\
\text { (min) }\end{array}$ & 182875 & 104840 & 160500 & 145000 & 74000 & 368000 \\
\hline Amyloid(mg/L) & Data in & patients: & 1 patient 3 & ; 2 patient & & \\
\hline
\end{tabular}

Results: We identified 9 patients:6/9 were male, median age at fever onset 1.33 years old IQR(0.46-4), age at diagnosis of sAID 3.8 years old
IQR(1.75-7). Clinical presentation included fever(9/9), abdominal pain and arthromyalgia(7/9), aphthous(6/9), headache, rash and adenopathy(5/9), delayed growth(4/9), tonsillitis and pericarditis(3/9) as well as diarrhea and pleuritis(2/9). One patient presented with stroke, cutaneous lesions, vasculopathy and haemolytic uraemic syndrome and 1 patient with amyloidosis and secondary hepatosplenomegaly. None of the children suffered from uveitis or meningitis. The flares lasted a median of 14 days(IQR 820). Two patients had persistent symptoms. Their mean/median lab values are shown at table. 4/9 patients had homozygous mutations with uncertain significance, heterozygous mutations or polymorphism but their symptoms or familiar study was not suggestive of the corresponding AID. One patient had an heterozygous mutation in MEFv (p.P3696,p.R408q) and also a CECR1 heterozygous mutation with uncertain significance, one patient had $\mathrm{pR} 92 \mathrm{Q}$ heterozygous mutation in TNFRSF1A, one patien had MEFv pR202Q homozygous mutation, other patient had a NOD-2 heterozygous mutation and the patient with amyloidosis had

INO80 deficiency and a NOD2 mutation (p.A918D). All patients responded to steroid therapy; subsequently $8 / 9$ received anti $\mathrm{IL}-1$ Receptor kineret as first biological therapy and $1 / 9$ with suspected vasculop athy received anti-TNF. Response to $\mathrm{IL}-1 \mathrm{R}$ antagonist was complete in $3 / 8$ and partial in $4 / 8$ children;1/8 showed no response. $2 / 8$ patients were switched to anti-TNF: One each to etanercept and Infliximab with good response. The patient with amyloidosis was changed to anti IL-6R with incomplete response but clear improvement compared to anti II-1R response. The patient with suspected vasculopathy and initial anti-TNF treatment had partial response with no recurrent stroke but persistent skin lesions.

Conclusion: An important group of patients with sAID lack genetic confirmation. Empirical use of $\mathrm{IL}-1 \mathrm{R}$ antagonist is promising but not effective in all patients as it was observed in our case series, where $5 / 8$ children showed partial or no response, $3 / 5$ needing a second biologic treatment in form of anti-TNF due to persistent moderate-severe symptoms.

A model to predict the response to different therapeutic strategies, based on clinical features and immunological profile (including inflammatory cyto kines) might help to choose the most appropriate immunomodulatory treatment.

Disclosure of Interests: None declared

DOI: 10.1136/annrheumdis-2019-eular.6220

\section{AB0976 PSYCHIATRIC DISORDERSDURING TRANSITION CARE IN ADOLESCENTS WITH RHEUMATIC DISEASES}

FERNANDO GARCIAA-RODRIGUEZ ${ }^{1}$, Lucero Ochoa-Alderete ${ }^{1}$, Antonio LópezRangel $^{2}$, Daniela Padilla ${ }^{3}$, Ana Villarreal-Trevino ${ }^{2}$, María Eugenia Corral Trujillo ${ }^{3}$, Ana Cecilia Arana Guajardo ${ }^{3}$, Roberto Negrete $^{3}$, Brenda Fortuna ${ }^{2}$, Manuel E. De la O-Cavazos ${ }^{1}$, Dionicio Ángel Galarza-Delgado ${ }^{3}$, Nadina Rubio ${ }^{1} .{ }^{1}$ UNIVERSIDAD AUTÓNOMA DE NUEVO LEÓN, HOSPITAL UNIVERSITARIO "DR. JOSÉ E. GONZÁLEZ", PEDIATRICS, MONTERREY, MeXICO; ${ }^{2}$ UNIVERSIDAD AUTÓNOMA DE NUEVO LEÓN, HOSPITAL UNIVERSITARIO "DR. JOSÉE. GONZÁLEZ", PSYCHIATRICS, MONTERREY, MEXICO; ${ }^{3} U N I V E R S I D A D$ AUTÓNOMA DE NUEVO LEÓN, HOSPITAL UNIVERSITARIO "DR. JOSÉ E. GONZÁLEZ", RHEUMATOLOGY, MONTERREY, MeXico

Background: Chronic rheumatic diseases (CRD) have a strong impact on psychosocial development of pediatric patients. There are several factors associated with psychiatric disorders (PD) in these children; physical disability, complex treatments, long-term follow-up, and flares, are the most cited in literature.

Juvenile Idiopathic Arthritis (JIA) is the first cause of disability in children with CRD, on the other hand, Major Depressive Disorder (MDD) and Dysthymia are the third cause. Some PD, mostly MDD, appear as a consequence of disability caused by $\mathrm{CRD}$, but immune pathways might be implicated in pathogenesis as well.

Adolescents with CRD need to transition to an adult-centered care while deal with emotional and physical changes. This implies a difficult situation in which patients could be in higher risk for develop PD. There are a lack of information on how this process affects emotional health in this population.

Objectives: The aim of the study is to calculate the prevalence of PD in adolescents with CRD during transitional care and their relationship with clinical and social factors.

Methods: Patients older than 16 years with an established CRD, who were in transitional care during the period between July 2017 and Janu ary 2019 were included in this transversal study.

We used MINI KID assessment tool to characterize PD in our patients. Each patient performs an interview with both a clinical psychologist and 